\title{
Modeling Scheme of Supervisory Control System for Electric Vehicle Charging Station Based on IEC61850
}

\author{
Shuguang $\mathrm{Liu}^{1}$, Wenbin $\mathrm{Lu}^{2}$ and Huawei Xie \\ ${ }^{1}$ School of Mechatronic Eng., Huangshan University, Huangshan 245041, China \\ ${ }^{2}$ School of Electronic and Information Eng., Xi'an Polytechnic University, Xi'an 710048, China
}

\begin{abstract}
Electric vehicles with zero pollution, zero noise, driving a simple advantage has become the focus of attention, but the battery life is weak and charging is not convenient and so on, has become a major obstacle to limit the use of large-scale. Therefore, it is imperative to develop the charging pile and charging station. According to requirements of electric vehicle (EV) charging station and its development trend, a modeling scheme of supervisory and control system for EV charging station based on IEC61850 series standards is put forward. In addition, an EV Charging station system model, device information model and communication model are also established, and its modeling methods are introduced. The implementation of intelligent electronic device (IED) information integration and the application prospect of system solutions are also presented.
\end{abstract}

Keywords-electric vehicle; charging station; supervisory and control system; intelligent electric device; IEC61850

\section{INTRODUCTION}

In order to alleviate the growing energy crisis and the environmental crisis, the auto industry must be toward the direction of cleaning, environmental protection, energy saving, and the development goals in countries all over the world to develop electric vehicles. Electric cars powered by car power supply, when after the battery power runs out, it is necessary to charge the battery and charging system is indispensable to the electric vehicle subsystems.

At present, has begun building AC charging across the country to promote the development of electric vehicles, on accelerating the construction of electric vehicle charging infrastructure, in guidelines (State Office (2015), 73rd), she said that "by 2020 into a moderate lead, car quest, intelligent and efficient system of charging infrastructure, meet the needs of more than 5 million electric car charging ... ... In principle, new residential construction of parking spaces, large public buildings, parking, public parking lots or proportion of spaces reserved for building charging infrastructure installation conditions are $100 \%, 10 \%, 10 \%$, per 2000 electric vehicles built at least a public charging station ". So many post must be equipped with sophisticated monitoring system to ensure safe and reliable operation of the charging system, in order to effectively charge to a range of monitoring, analysis and assessment, the operating personnel in charge and the later decision analysis are of great practical significance.
Charging electric vehicle charging station Basic consists of machines, control systems, safety protection facilities and other supporting facilities [1]. Among them, the monitoring system is to charge, distribution, metering and billing, security and other related automation system integration as a whole, in the realization of supervisory control and data acquisition (SCADA) functions on the basis of, in accordance with the actual characteristics of the charging station, including comprehensive monitoring, intelligent load control equipment and the effective interaction of the grid control and management [2].

Electric vehicle charging station monitoring and control system is linked to electric vehicles and recharging station monitoring center, electric power dispatching Center information focal point, information exchange is the tendency of large-scale electric vehicle development. [3-5] refers to electric vehicle recharging station monitoring and control system-building program to meet the monitoring requirements, but no specification for data interchange, data model, and the model, therefore, open system cannot meet the requirements of future development. Electric vehicle charging station monitoring and control system should be a model, standardized communications systems, and the ability to meet the requirements of standardization of information exchanges, so as to avoid information silos and duplication.

This paper will be introduced to the IEC61850 electric vehicle charging station monitoring system, the charging system structure model of system based on IEC61850 standard, the station of intelligent electronic devices (IED) communication information model and communication model research based on IEC61850 standard, the formation of a unified system model, information model and communication model, make the building monitoring system have good openness and interoperability, enhance the efficiency of management system operation.

\section{ChARging StATION MONITORING SYSTEM ARCHITECTURE}

Electric vehicle charging station monitoring system is mainly composed of intelligent monitoring and control system integration, the host of concentrator and various IEDs and communications equipment. System function mainly includes the charging system of measurement and control, protection and metering equipment, measurement and control of a power 
distribution system equipment and protection, monitoring of environment, security, etc as well as to monitor "dispatch center data forwarding. As shown in Fig. I for an electric vehicle charging station monitoring system architecture.

Electric vehicle charging station data flow mainly has three nodes: collection, collection and integration, the corresponding collection station intelligent sensor, integrated intelligent devices and on-site monitoring system. There are two communication interface: integrated intelligent information collection device or automation monitoring device and the interface between the station monitoring system; Interface between intelligent sensor and integrated intelligent collection device. There is also with electric vehicle charging station monitoring center or the interface between the electric power dispatching center. The communication interface between the need to have standard information model and communication model for data interaction, can efficiently realize the monitoring and interactive functions.

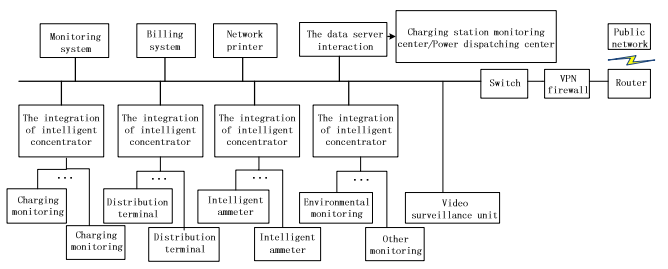

FIGURE I. CHARGING STATION MONITORING SYSTEM WITH SINGLE-WIRE STRUCTURE

According to the functional requirements of electric vehicle charging station system, gives the support technology of electric vehicle charging station monitoring system architecture, as shown in Fig. II. Among them, the system model and information model is the foundation of the whole support technical system, the communication model of information interaction system model is the description of the structure of the electric vehicle charging station system specification, the information model is the specification for each interaction imformation semantic, communication model is station information integration and interaction of specification. The above each IED model based on the research and implementation of IEC61850 standard, charging station can be implemented system seamless data exchange and information sharing.

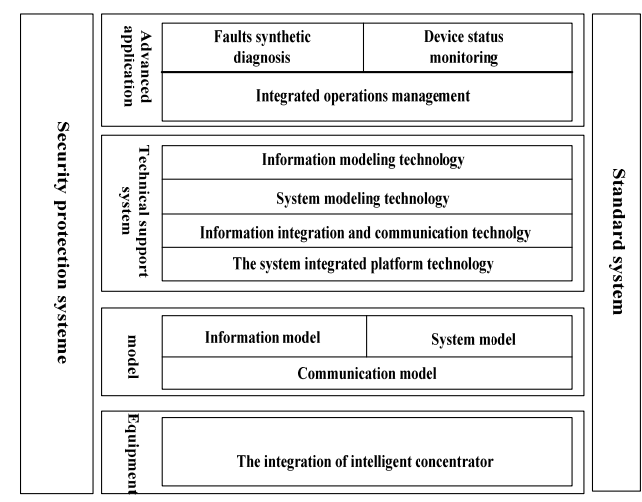

FIGURE II. SUPPORT TECHNOLOGY ARCHITECTURE

\section{STATIONS SYSTEM MODELING}

System model is the foundation of the system design and analysis. The representation of electric power system model is the main node/switch model and the model for bus/branch. Node/switch model contains power system real time required for operating the field device and its connection relationship, state information, such as measurement information [6] for more information. A large electric vehicle charging station system function structure is shown in Fig. III. Among them, the power distribution equipment both transformer, circuit breaker, breaker, bus, such as a device, also have protection/secondary equipment such as measurement and control device; Charging equipment has a charger, AC/DC charging pile; Auxiliary equipment such as environment/security equipment. System model is not only to reflect the system structure and the connection of the relation between electrical equipment, also want to reflect and dependencies between the IED.

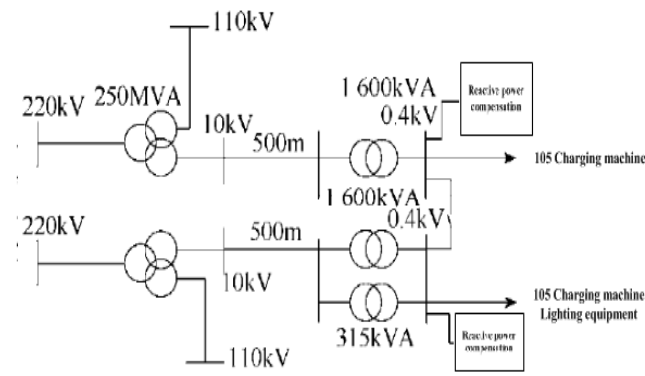

FIGURE III. STATIONS SYSTEM STRUCTURE

Electric vehicle charging station system model has a variety of display, the most commonly used is a tree structure. During tree display to determine the hierarchy model of electric vehicle charging station resources, request must have a root node, and each child nodes of the parent node is the only [7]. According to the characteristics of the electric vehicle charging station resources with tree structure model, as shown in Fig. IV.

Electric vehicle charging station as the root node, and it includes voltage grade distribution transformer, security, environmental monitoring equipment belong to the root node, also belonging to the root node. $10 \mathrm{kw}$ voltage level contains the circuit breaker, knife switches, power distribution equipment and protection, measurement and control equipment; $400 \mathrm{v}$ voltage levels in addition to the relevant distribution equipment and charging equipment, such as dc power charger, charging pile not only has the function of power supply, also the function of measurement and control, protection, measurement, such as combination. No battery in the system model is separated from car charger modeling, they connect directly charging pile, are described in the equivalent load. 


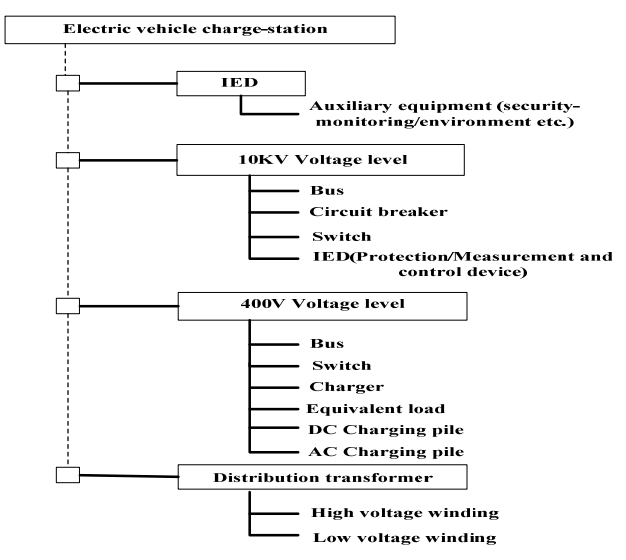

FIGURE IV. CHARGING SYSTEM MODEL

Language is based on CIM/XML resource description framework (RDF) application of CIM, the CIM is, the resource description framework (RDF Schema), RDF syntax. In $\mathrm{CIM} / \mathrm{XML}$ document used all the tags are made by RDF Schema definition, makes the document can be parsed and realize the heterogeneous systems information exchange.

Therefore, the electric vehicle charging station system model reference to describe the CIM/XML, through equipment belonging to attributes describe the father-son relationship, the connection attributes describe the connection of the equipment, associated attributes describe the scope of the relationship between devices. According to the above model, $10 \mathrm{KV}$ power distribution equipment and related testing equipment belonging to attribute associated with $10 \mathrm{KV}$ voltage grade, power distribution equipment connection properties reflect the bus, circuit breaker, breaker connection relationship. Measurement and control/protection device is to place a child node with distribution equipment, but no connection relationship, with associated attributes describe the scope of the relationship between the primary and secondary equipment. Equivalent load and charger and ac/dc charging pile under properties associated with the $400 \mathrm{v}$ voltage grade, the correlation property description ac/dc charging pile and its corresponding equivalent load or charger scope, the connection attributes reflect the ac/dc charging piles and the corresponding equivalent load or connected to the charger. Environment/security equipment directly through its affiliated attributes associated with charging stations. In accordance with the above approach, the level of the electric vehicle charging station can be determined most resource, connection, and the scope of the relationship between its equipment.

\section{APPLICATION FUNCTION REQUIREMENT ANALYSIS}

\section{A. Charging Monitoring Function}

Charging monitoring function is the core of the charging station monitoring system, the main implementation of monitoring and control of charging pile and charger.

\section{1) Monitoring of charging pile}

Monitoring the status of charging pile of AC output interface, such as current, voltage, switch state and protection status, etc.; Acquisition and charging pile connecting the basic information of the electric car; Control the charging pile of AC output interface open.

\section{2) Monitoring of charger}

Charger as a monitored object, to monitor and control system on data mainly include two categories: charger status information, namely, input and output voltage, current, power, power factor, charging time and current charging mode, charging machine fault status, etc.; Battery status information, namely, basic information battery pack, battery monomer, monomer battery temperature and battery voltage fault state, battery management system set up information, etc.

The charger control function mainly includes: to start, stop, emergency stop charging charger control; Adjust the charger charging mode, namely, depending on the type of charger connected to the battery and charging characteristics, operating personnel charging parameters can be adjusted by graphic images of different stages, and send to charger; Distributed to the charger and connect the battery management system command for fashion.

\section{B. Distribution Monitoring Function}

Implementation of electric vehicle charging station monitoring of power distribution equipment, convenient and unified management and data sharing, which can realize the total power of the site, the total current, total power, power factor, main transformer, switch state, reactive power compensation and harmonic control equipment monitoring and control.

\section{Smoke Monitoring Function}

In order to ensure the security of the battery, in addition to the battery management system to monitor the battery voltage, temperature, installed in the battery charging rack number of smoke sensor to detect lithium ion power battery cell spontaneous combustion caused by overcharge and release of smoke. These sensors are connected to the charging station monitoring system, monitoring and controlling of the charging function (especially when the battery management system) together to protect the safety of the battery.

\section{Battery Maintenance Monitoring Function}

In large charging stations, they need to pass a special battery maintenance equipment regular maintenance on batteries. In the process of maintenance, the maintenance of system will be collected data into database, charging station monitoring system to form the battery full data files, an overall evaluation of the battery.

\section{The Realization Of the Charging Station MONITORING SYSTEM}

\section{A. System Structure}

Reference current charging monitoring system and technical implementation route and development trend of electric power monitoring and control system, the platform, modular, modular design thought, charging station monitoring system was designed and developed in this paper. The system consists of foundation platform, support platform and application system, the system structure is shown in Fig. V. 


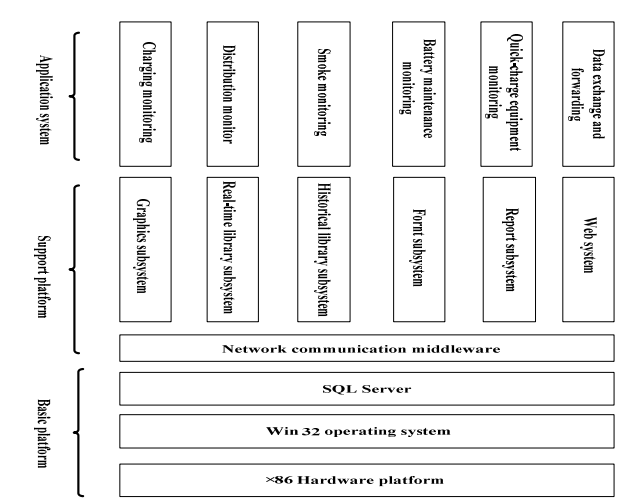

FIGURE V. CHARGING STATION MONITORING SYSTEM STRUCTURE

Monitoring system platform by X86 hardware platform and the Win32 OS and Microsoft SQL Server database system structure. System support platform by the network communication middleware, graphics subsystem, real-time database subsystem, historical data subsystem, front subsystem, report subsystem, Web publishing subsystem, etc. Network communication middleware, real-time database subsystem, historical library subsystem, front-end subsystem provides abundant secondary development interface.

\section{B. The Application Situation}

The monitoring system has been successfully applied in a large electric bus charging stations. The system implements the charging stations within 210 points box charging machine and four emergency charger charging process monitoring and control as well as to the 300 battery holder smoke sensor, remote communication information collection. System network structure as shown in Fig. VI.

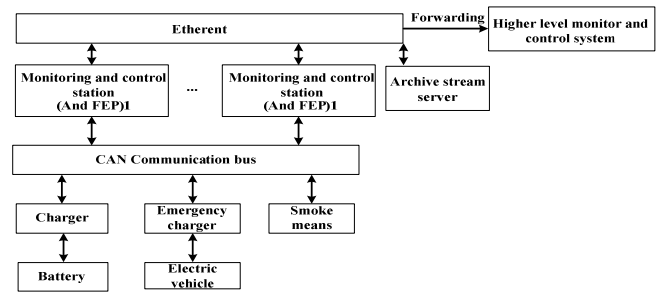

FIGURE VI. SYSTEM NETWORK

Each charging district staff can master monitor screen as shown in Fig. VII by the charger monitors the current operating state, the battery state of charge and the corresponding smoke sensor status.

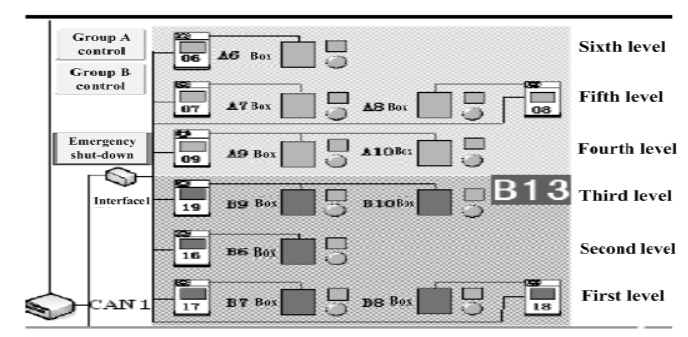

FIGURE VII. PARTITION MAIN CHARGE MONITOR SCREEN
The staff can also monitor the picture on the monitor information current charger output voltage, current, power, charging failure status, charging status by the charge pattern information shown in Fig. VIII charger or battery pack, the battery pack is connected to the charger's.

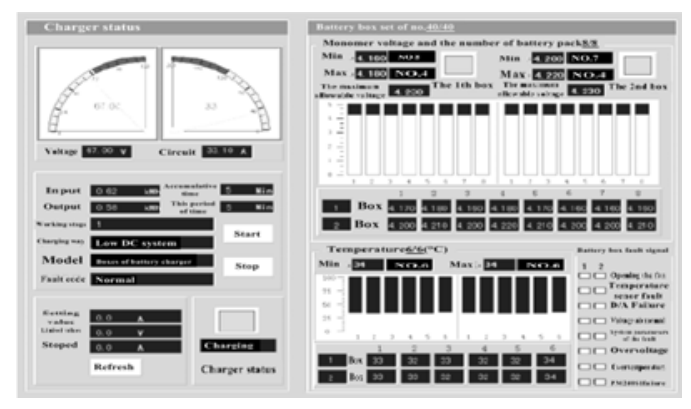

FIGURE VIII. BATTERY CHARGING MONITOR SCREEN

\section{CONCLUSION}

As domestic electric vehicle demonstration operation of the industrialization, large-scale carry out and still need in the following several aspects to conduct the thorough research to the electric vehicle charging station monitoring system:

1) Research and functional specifications for electric vehicle charging station monitoring system, research and develop and charging station monitoring system, battery charger, rechargeable pile maintenance equipment such as communication protocol. In addition, as the switching function of electric vehicle charging station, in a specific area more data exchange between the electric vehicle charging station, electric vehicle charging station monitoring system data exchange between the standard of research is also required.

2) The study of electric vehicle charging stations and volatility power integrated control technology, realize the electric car recharging equipment start-stop, rechargeable power regulation and charging stations available input power automatic and intelligent coordination control.

\section{REFERENCE}

[1] Q/CSG11516.7-2010. Electric vehicle charging station monitoring system specification [S]. Guangzhou, China southern power grid co., LTD., 2010.

[2] Li Huiling , BAI Xiaomin. The influence of the electric vehicle charging on the distribution network and countermeasures [J]. Automation of electric power systems, 2011, 35 (17): 38-42.

[3] ZHAO Mingyu, WANG Gang, WANG Yinghui, etc. Electric vehicle charging infrastructure monitoring and control system design and implementation of [J]. Automation of electric power systems, 2011, 35 (10): 65-69.

[4] YAN Hui, LI Gengyin, 24-year-old, etc. The design and implementation of electric vehicle charging station monitoring system [J]. The grid technology, 2009 (12): 15 to 19.

[5] WANG Yunyan, JIANG Jiuchun NIU Liyong. Electric vehicle charging station management system [J]. Microcomputer development, 2005, 15 (11): 57-59.

[6] WANG Lei, MI Zengqiang, REN Hui, etc. The study of the model of power system based on CIM/XML [J]. China power education, 2006 (suppl 1) : 106-108.

[7] XIE Shujing, WANG Hao, ZHANG Zhiwei. Power grid based on CIM modeling problems [J]. Grid and clean energy, 2011, JK27 (2) : 37-47. 